\title{
Novel Cascade Solar Desalination Still: Mathematical, Numerical and Experimental Analysis
}

\author{
M. Bouzaid ${ }^{1, *}$, N. Mouhsin ${ }^{1}$, M. Taha-Janan'1, M. Oubrek ${ }^{1}$, O. Ansari ${ }^{1}$
}

1. PCMT, Laboratoire de Mécanique Appliquée et Technologies, Centre de Recherche en Sciences et Technologies Industrielles et de la Santé, ENSET, Mohammed V University in RABAT, Avenue de l'Armée Royale, BP 6207 Rabat-Instituts, MOROCCO

*mariambouzaid.91@gmail.com

\begin{abstract}
Morocco is considered as a water-stressed country and is among the countries that face fresh water scarcity. However Morocco has an important solar energy and a significant amount of seawater and ocean. Therefore converting saline water to fresh water using solar energy is the perfect and the cleanest solution. Solar still is the simplest, cleanest and cheapest technology of solar desalination. In this paper a novel solar still with stepped-slope absorber plate and baffles was proposed and developed in order to enhance the thermal performance of the conventional solar stills. In order to validate the performance of the developed technology a comparative study were elaborated. A mathematical model was developed. The energy balance equations for the various elements of the solar still are formulated and numerically solved using the dynamic simulation program Matlab/Simulink ${ }^{\mathrm{TM}}$ and the Euler explicit method programmed by $\mathrm{C}++$. Also, the experimental process of the new construction was evaluated and validates the new pattern performance. The thermal performance was investigated and shows considerable improvement through the new construction.
\end{abstract}

Keywords: Solar desalination, brackish water, stepped solar still, cascade solar still, heat transfer;

\section{Introduction}

Water resources in Morocco are limited and unevenly distributed. The demand for fresh water is also increasing because of demographic growth, industrial and agricultural development. For these reasons Morocco can be considered as one of the Water-Stressed countries. Solar desalination is considered as the cleanest technology of saline water purification. The solar stills have received much attention because their process is simple, cheap and are easy to fabricate. Solar stills or simple basin solar stills are the simplest devices in term of use, manufacturing and maintenance. This type of desalination is cheap in comparison with the industrial techniques and can be easily installed in the rural areas or at home in the case of the existence of salt water wells. In this paper, a new approach of desalination using directly the solar energy has been analyzed and realized. The aim of the project is to improve the thermal performance of simple basin solar still by developing a new design of solar still absorber plate. A mathematical model and thermal analysis were formulated in order to investigate the performance of the modified stepped solar still. The thermal model is numerically solved using the dynamic simulation program Matlab/Simulink ${ }^{\mathrm{TM}}$ to validate numerically and mathematically the new solar still performance before the construction. A numerical code was also developed in $\mathrm{C}++$ program, tested and used to carry on the present study. An experimental process was realized at the Higher Normal School of Technical Education (ENSET) of Rabat-Morocco $\left(34^{\circ} 47^{\prime} \mathrm{N}\right)$ and experimental data were collected on 27 , 28 and 29 of March 2017 to validate the elaborated model.

\section{System Description}

The present work is an extension of first attempt of modeling the new device by Bouzaid et al. [1]. The absorber plate is in the form of stairs made of a number of steps. The classical ordinary form of stairs has horizontal and vertical surfaces; the angle between the two surfaces is about $90^{\circ}$. As indicated in [1], in the new design the glass cover and the vertical surface of absorber plate are inclined with angles of $25^{\circ}$ and $35^{\circ}$ respectively for better orientation relative to the sun. The Absorber plate inclination was equal to the latitude of Rabat $\left(34^{\circ} 47^{\prime} \mathrm{N}\right)$. Our pattern consists, as shown in Fig.1, of horizontal and vertical/inclined types of absorber plates and the angle between the two surfaces was about $145^{\circ}$. In order to improve the performance of cascade solar still, the water transit time on the absorber plate should be maximized. Therefore, in the new design, different weirs were added on the sloped absorber plate.

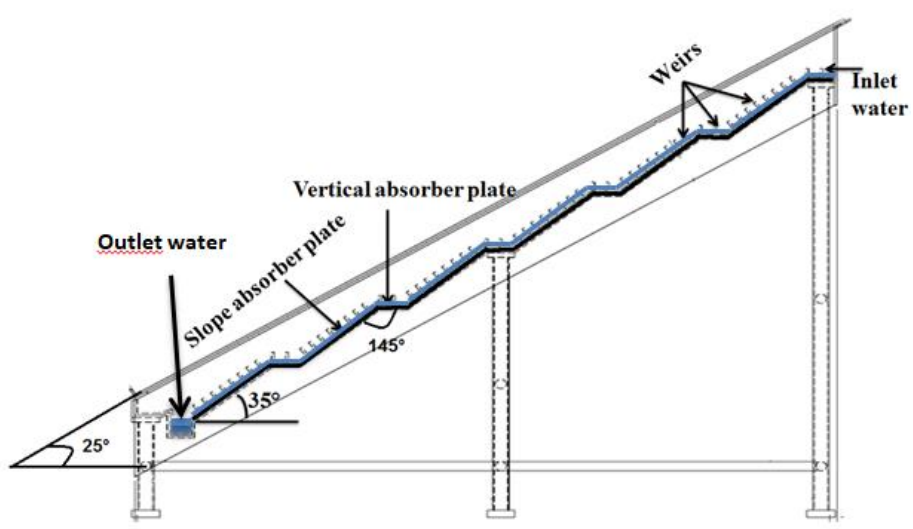

Fig.1. Schematic sketch of the new stepped absorber plate (with slope surface and weirs) 


\section{Results and Discussion}

A mathematical model was developed and validated to evaluate the thermal performance of the novel soar still. The energy balance equations for the various elements of solar still are formulated and numerically solved by using two methods. The first method uses the Runge Kutta- Fehlberg algorithm, with the dynamic simulation program Matlab/Simulink ${ }^{\mathrm{TM}}$. The second one is based on the Euler explicit method and programmed by $\mathrm{C}++$. A comparative study between the conventional and the new solar has been made.

Figure 2 represents the variation of absorber plate temperature from the experimental results for the ordinary still developed by Ahmad Banakar in in 2013[2] and our new design of the absorber plate (stepped absorber plate with slope surfaces and weirs). It is inferred from figure 3 that the absorber plate temperature in the still with slope surfaces and weirs is higher than that of the normal form.

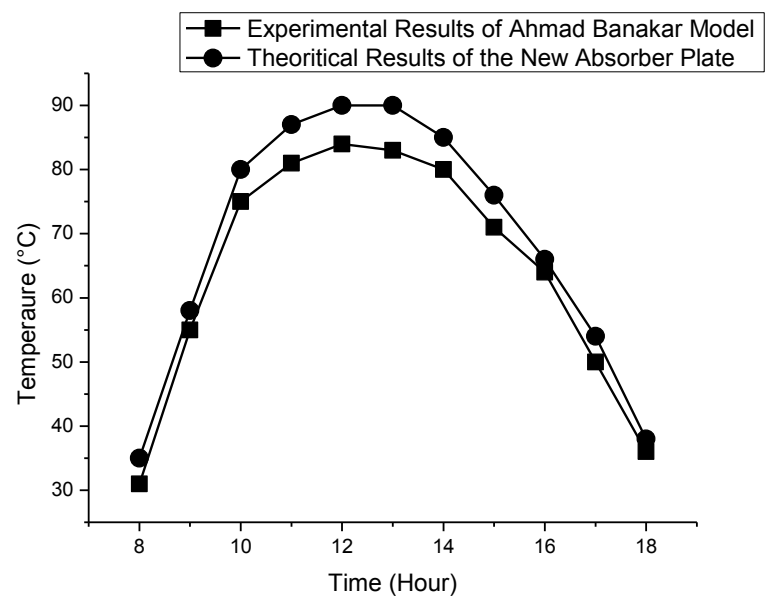

Fig.2. Variation of absorber plate temperature based on Ordinary solar still results and model results of our new design of the absorber plate (stepped absorber plate with slope surfaces and weirs). Using Matlab/Simulink ${ }^{\mathrm{TM}}$.

Figure 3 represents a numerical evaluation of the new model (inclined and stepped absorber plate with slope surfaces and baffles). By comparing the results of the novel design and the experimental data of the conventional solar still collected by El-Sebaii et al. [3], it is inferred that the brackish water and the absorber plate temperature in the still with slope surfaces and weirs is higher than that of the conventional model.

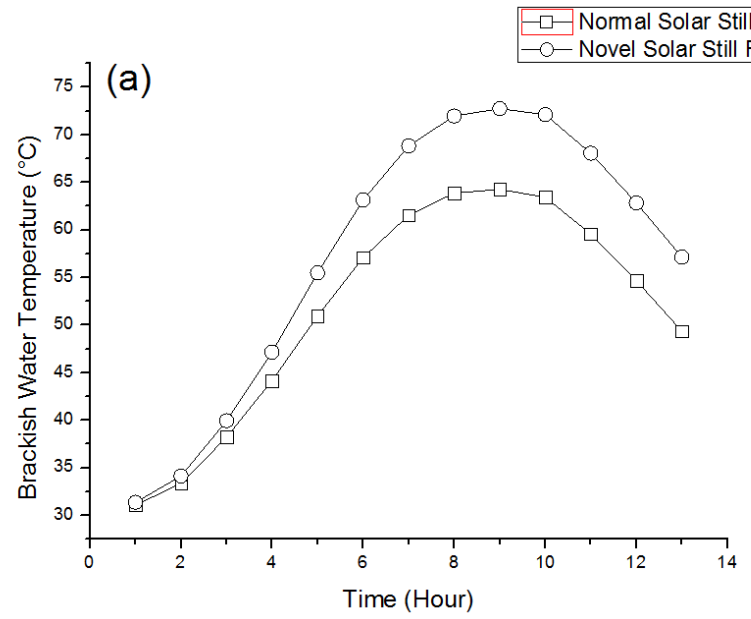

(b)

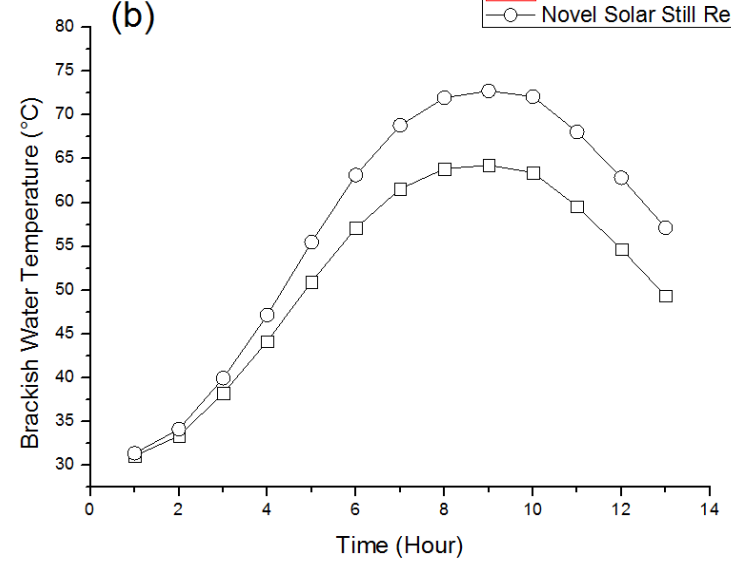

Fig. 3. Numerical comparison between the novel solar still and the normal solar still. (a) Brackish Water Temperature and (b) Absorber Plate Temperature. Using Program C++.

A comparative study between the numerical model that has already been validated and the experimental data of the new cascade solar still was elaborated.

Figure 4 illustrates the hourly variation of the absorber pate temperature measured and the solar radiation data collected on 27 March 2017. As it can be seen from the illustrations, the behavior of the absorber plate temperature has the same variation of solar intensity. The absorber plate temperature, shown in figure 4 increases with an increase of solar radiation. In addition, it can be observed from figure 7 that the maximum of absorber plate temperature occurs at maximum of solar insulation. Also, the absorber plate temperature can reach $68.5^{\circ} \mathrm{C}$ for $873 \mathrm{~W} . \mathrm{m}^{-2}$ of solar intensity which is an important value of temperature in comparison with others solar stills results.

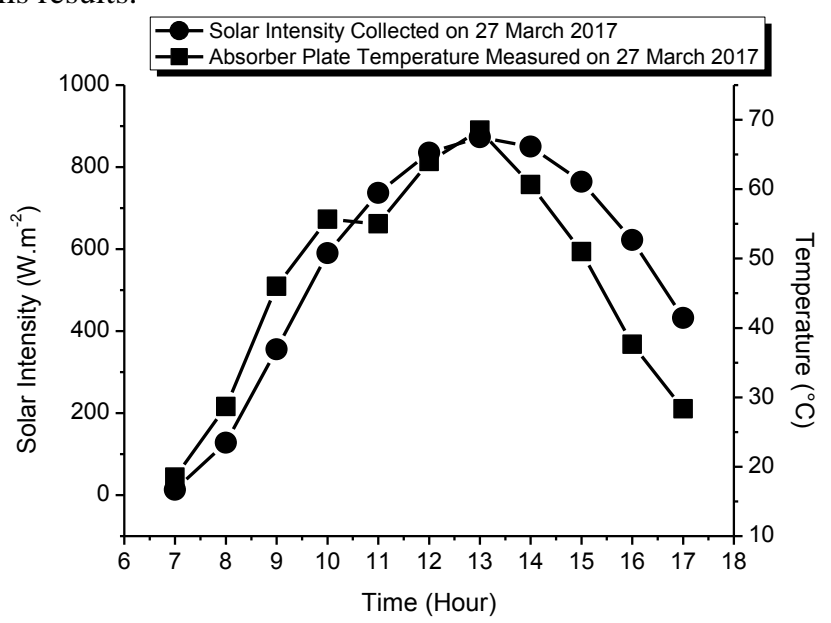

Fig.4. Hourly variation of solar radiation and the absorber plate temperature measured on the 27 March 2017.

Figure 5 shows the variation of hourly productivity, based on the experimental results for the new design of the absorber plate (stepped absorber plate with slope surfaces and weirs).

From figure 5 it is found that there is an increase in the water productivity during early hours of the day until it reaches the maximum water productivity around midnoon during the three days. The hourly productivity can 
reach $1.3 \mathrm{~kg} / \mathrm{m}^{2} \mathrm{hr}$ for $873 \mathrm{~W} . \mathrm{m}^{-2}$ of solar intensity in the first day (27 March 2017), $1.5 \mathrm{~kg} / \mathrm{m}^{2} \mathrm{hr}$ for 826 $\mathrm{W} . \mathrm{m}^{-2}$ in the second day (28 March 2017) and 1.4 $\mathrm{kg} / \mathrm{m}^{2} \mathrm{hr}$ for $776 \mathrm{~W} . \mathrm{m}^{-2}$ in the third day (29 March 2017), that are very interesting values in comparison with other solar stills results.
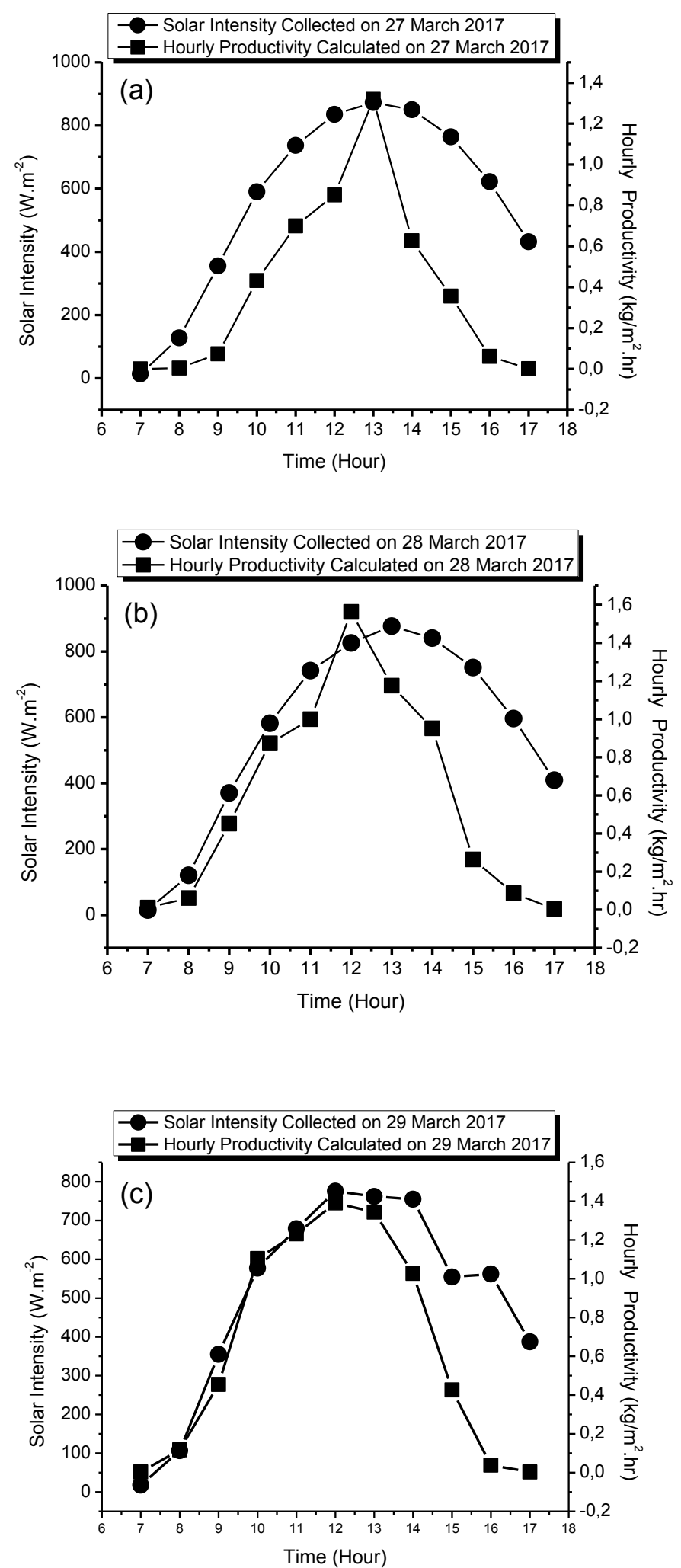

Fig.5. Hourly variation of solar radiation and the hourly productivity of the still

(a) 27 March 2017, (b) 28 March 2017, (c) 29 March 2017

\section{Conclusion}

A new type of inclined solar still with cascade absorber plate, slope surfaces and baffles was developed, fabricated and evaluated in order to improve the efficiency of the single basin solar still.

The energy balance equations are formulated and numerically solved using a simulation program. A new pattern of stepped solar still was fabricated and tested during $11 \mathrm{~h}$ during three days. The thermal performance of the novel solar still was investigated theoretically, numerically and experimentally.

The results indicate that the new design improves the brackish water and the absorber plate temperature and so the thermal performance of a modified stepped solar still can be considerably improved through the new modification.

In comparison with other solar still results, the daily production of the new cascade solar still can reach important values, more than $4 \mathrm{~kg} / \mathrm{m}^{2}$ day in the first day, $6.43973 \mathrm{~kg} / \mathrm{m}^{2}$ day in the second day and more than $7 \mathrm{~kg} / \mathrm{m}^{2}$ day at the last day.

\section{References}

[1] M. Bouzaid, O. Ansari, M. Taha-Janan, M.Oubrek, Experimental and Theoretical Analysis of a Novel Cascade Solar Desalination Still, Fluid Dynamics \& Materials Processing, FDMP, vol.14 (2018) no.3, pp.177-200

[2] M. Montazeri, A. Banakar, B. Ghobadian, Design and Evaluation of a New Absorber Plate for Cascade Solar Still, Technical Journal of Engineering and Applied Sciences (2013).

[3] El-Sebaii, Al-Ghamdi, Al-Hazmiand and Faidah Adel, Thermal performance of a single basin solar still with PCM as a storage medium, Applied Energy vol.36 (2009) pp. 1187-1195. 